\title{
Proline accumulation induced by excess nickel in detached rice leaves
}

\author{
Y.C. LIN and C.H. KAO* \\ Department of Agronomy, National Taiwan University, Taipei 106, Taiwan, Republic of China
}

\begin{abstract}
The regulation of proline accumulation in detached rice leaves exposed to excess $\mathrm{NiSO}_{4}$ was investigated. $\mathrm{NiSO}_{4}$ treatment increased proline and $\mathrm{Ni}$ contents but had no effect on relative water content, indicating that proline accumulation in $\mathrm{Ni}$-exposed detached rice leaves was due to $\mathrm{Ni}$ uptake per se, rather than to water stress. Proline accumulation caused by $\mathrm{NiSO}_{4}$ was related to protein hydrolysis, a decrease in proline dehydrogenase activity, and a decrease in proline utilization. It seems that an increase in the content of ammonia and an increase in the activities of $\Delta^{1}$-pyrroline-5-carboxylate reductase and ornithine- $\delta$-aminotransferase play minor if any role in Ni-induced proline accumulation in detached rice leaves.
\end{abstract}

Additional key words: glutamic acid, ornithine, ornithine- $\delta$-aminotransferase, Oryza sativa, proline dehydrogenase, $\Delta^{1}$-pyrroline5-carboxylate reductase.

Nickel (Ni) is an essential element for plant growth (Brown et al. 1987). In general, there is much more concern about Ni toxicity in crop plants. Critical toxicity levels in crop species are in the range of $>10 \mu \mathrm{g} \mathrm{g}^{-1}$ (d.m.) in sensitive, and $50 \mu \mathrm{g} \mathrm{g}^{-1}$ (d.m.) in moderately tolerant species (Marschner 1995). At toxic concentrations $\mathrm{Ni}$ interferes with plant growth and metabolism (Mishra and Kar 1974). Some plant species are adapted to grow on soil containing high content of Ni. Such plants were named Ni hyperaccumulators. Recently, shoot cultures of Alyssum markgraffi, endemic $\mathrm{Ni}$ hyperaccumulating species, were established and maintained on Murashige and Skoog medium (Vinterhalter and Vinterhalter 2005). Nakazawa et al. (2004) demonstrated that histidine is involved in Ni-tolerance and detoxification of $\mathrm{Ni}$ in symplast in Ni-tolerant tobacco cells.

Many plants accumulate proline when treated with toxic concentrations of heavy metals (Alia and Pardha Saradhi 1991, Bassi and Sharma 1993a,b, Costa and Morel 1994, Schat et al. 1997, Metha and Gaur 1999, Chen et al. 2001, Rai 2002). Metha and Gaur (1999) reported that excess $\mathrm{Ni}$ caused proline accumulation in Chlorella vulgaris. However, this is the only report describing proline accumulation under Ni stress so far. It is not known whether other plant systems also show proline accumulation in response to $\mathrm{Ni}$.

Proline accumulation in plant tissues has been suggested to result from 1) an increase in proline biosynthesis, 2) a decrease in proline degradation, 3) an increase in protein hydrolysis, 4) a decrease in proline utilization (Charest and Phan 1990, Yoshiba et al. 1997). In plants, proline is synthesized from glutamic acid via $\Delta^{1}$-pyrroline-5-carboxylate (P5C) by two enzymes, P5C synthetase and $\mathrm{P} 5 \mathrm{C}$ reductase (P5CR, EC 1.5.1.2) (Delauney and Verma 1993,Yoshiba et al. 1997). Plants also synthesize proline from ornithine by ornithine- $\delta$ aminotransferase (OAT, EC 2.6.1.13). On the other hand, the content of proline also depends on its degradation, which is catalysed by the enzyme proline dehydrogenase (PDH, EC 11.5.99.8) (Yoshiba et al. 1997).

In detached rice leaves, it has been shown that proline accumulates during dark-induced senescence (Wang et al. 1982), by excess copper (Chen et al. 2001), by $\mathrm{NaCl}$ (Lin et al. 2002), by water stress (Hsu et al. 2003, Yang and Kao 1999), and by exogenous abscisic acid (Yang et al. 2000). This paper reports the results of an investigation into the regulation of proline accumulation in detached rice leaves exposed to excess $\mathrm{NiSO}_{4}$.

Received 10 June 2005, accepted 25 March 2006.

Abbreviations: d.m. - dry mass; f.m. - initial fresh mass; GABA - $\gamma$-aminobutyric acid; OAT - ornithine- $\delta$-aminotransferase; P5C - $\Delta^{1}$-pyrroline-5-carboxylate; P5CR - $\Delta^{1}$-pyrroline-5-carboxylate reductase; PDH - proline dehydrogenase; RWC - relative water content.

Acknowledgement: This work was supported by the National Science Council of the Republic of China.

* Corresponding author; fax: (+886) 02 23620879, e-mail: kaoch@ntu.edu.tw 
Rice (Oryza sativa L. cv. Taichung Native 1) was cultured in a stainless net floating on Kimura B nutrient solution $(\mathrm{pH} 4.2)$ in a $500-\mathrm{cm}^{3}$ beaker (Hsu and Kao 2005). The nutrient solution was replaced every $3 \mathrm{~d}$. Rice plants were grown for $12 \mathrm{~d}$ in a greenhouse, under natural sunlight and the day/night temperature of $30 / 25^{\circ} \mathrm{C}$. The apical $3 \mathrm{~cm}$ of the third leaf of 12-d-old seedlings was used for the experiment. A group of 10 segments floated in a Petri dish containing $10 \mathrm{~cm}^{3}$ of distilled water served as controls and $\mathrm{NiSO}_{4}(10 \mathrm{mM})$. All samples were kept at temperature at $27^{\circ} \mathrm{C}$ and irradiance of $40 \mu \mathrm{mol} \mathrm{m}^{-2} \mathrm{~s}^{-1}$ for $12,24,36$, and $48 \mathrm{~h}$.

Relative water content (RWC) was determined by the method of Weatherley (1950). For determination of proline, glutamic acid, ornithine, $\gamma$-aminobutyric acid (GABA), $\mathrm{NH}_{3}$, and total amino acids, leaf samples were extracted with $2 \%$ sulfosalicylic acid and the homogenates was centrifuged at $15000 \mathrm{~g}$ for $20 \mathrm{~min}$. The supernatant was used directly for amino acid analysis (amino acid analyzer, Beckman 63000, Palo Alto, USA). For protein determination, leaf segments were homogenized in $50 \mathrm{mM}$ sodium phosphate buffer ( $\mathrm{pH}$ 6.8). The homogenate was centrifuged at $17600 \mathrm{~g}$ for $20 \mathrm{~min}$, and the supernatants were used for determination of protein by the method of Bradford (1976). Enzymes were extracted and assayed as described previously (Chen et al. 2001). For determination of $\mathrm{Ni}$, leaf samples were dried at $65{ }^{\circ} \mathrm{C}$ for $48 \mathrm{~h}$. Dried materials were ashed at $550{ }^{\circ} \mathrm{C}$ for $4 \mathrm{~d}$. Ash residues were incubated with $17.5 \%$ (v/v) $\mathrm{HNO}_{3}$ and $17.5 \%(\mathrm{v} / \mathrm{v}) \mathrm{H}_{2} \mathrm{O}_{2}$ at $72{ }^{\circ} \mathrm{C}$ for more than $10 \mathrm{~h}$, and dissolved in double distilled water for $3 \mathrm{~h}$. Ni content was then quantified using an atomic absorption spectrophotometer (Shimadzu AA-6800, Kyoto, Japan).

Amino acids, protein, and $\mathrm{NH}_{3}$ were expressed on the basis of initial fresh mass (f.m.). Enzyme activity was expressed on the basis of protein. Ni was expressed on the basis of dry mass (d.m.). Statistical differences between measurements $(n=4)$ for different treatments or for different times were analyzed following the Duncan's multiple range test or Student's $t$-test.

Proline content in detached rice leaves exposed to $\mathrm{NiSO}_{4}(10 \mathrm{mM})$ increased significantly with the increase of incubation time (Fig. 1). It is clear that accumulation of proline induced by $\mathrm{NiSO}_{4}$ was evident $12 \mathrm{~h}$ after treatment (Fig. 1).

To be sure that the described proline accumulation was related to an increase in the leaf $\mathrm{Ni}$ content, $\mathrm{Ni}$ concentrations were determined in detached rice leaves treated with either water or $10 \mathrm{mM} \mathrm{NiSO}_{4}$ (Fig. 1). Ni content in control leaves remained unchanged during $48 \mathrm{~h}$ in the light. However, $\mathrm{Ni}$ content in $\mathrm{NiSO}_{4}$-treated detached rice leaves increased with increasing duration of incubation. It is obvious that the increase in Ni content in $\mathrm{NiSO}_{4}$-treated detached rice leaves was evident $12 \mathrm{~h}$ after treatment.

Rabe (1990) postulated that any stress causing reduced growth or impaired plant health will result in ammonia accumulation early and suggested that the ammonia detoxification results in the accumulation of nitrogen containing compounds, such as putrescine and proline. Exogenous $\mathrm{NH}_{4} \mathrm{Cl}$, methionine sulfoximine and phosphinothricin, which caused an accumulation of ammonia in detached rice leaves, increased proline content (Yang and Kao 2000, Tsai et al. 2003). In the present study, we also observed that $\mathrm{NiSO}_{4}$ treatment resulted in an ammonia accumulation (Fig. 1). However, Ni-induced ammonia accumulation was observed only after the onset of proline accumulation (Fig. 1). It appears that ammonia plays a minor if any role in proline accumulation by $\mathrm{NiSO}_{4}$ in detached rice leaves.

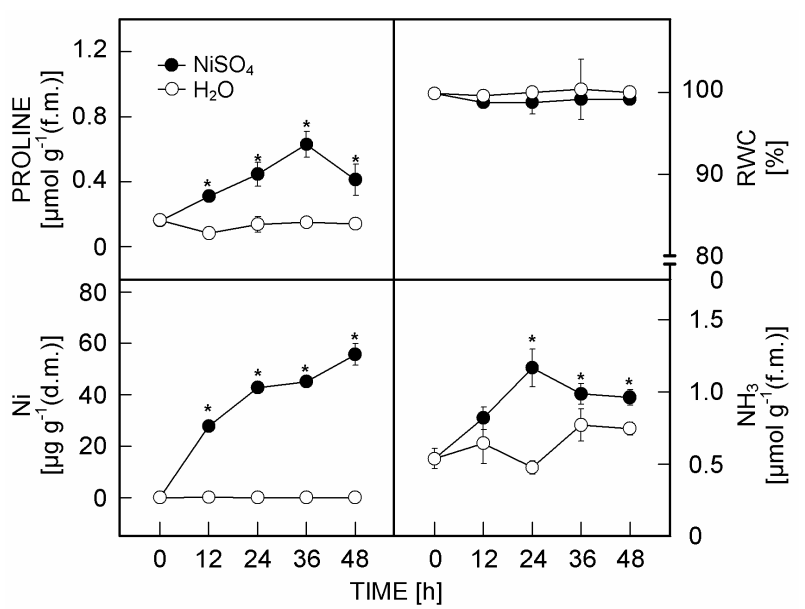

Fig. 1. The contents of proline, $\mathrm{Ni}$, and ammonia and relative water content (RWC) in detached rice leaves floating on water $\left(\mathrm{H}_{2} \mathrm{O}\right)$ or $\mathrm{NiSO}_{4}(10 \mathrm{mM})$ solution for $12,24,36$, and $48 \mathrm{~h}$. Means $\pm \mathrm{SD}, n=4$. Asterisks represent values that are significantly different between $\mathrm{H}_{2} \mathrm{O}$ and $\mathrm{NiSO}_{4}$ treatments at $P<0.05$ determined by Student's $t$-test.

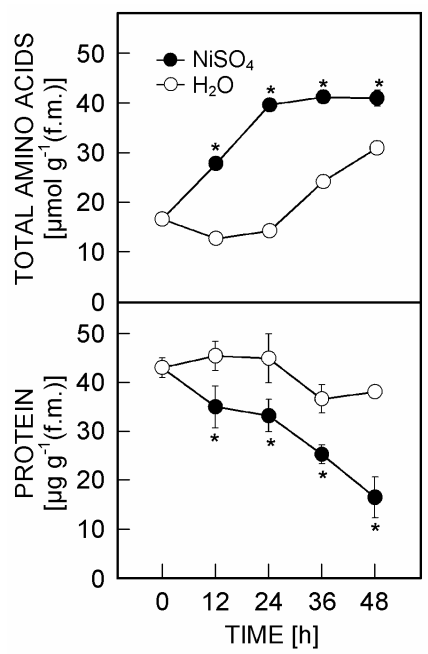

Fig. 2. The contents of total amino acids and protein in detached rice leaves floating on water $\left(\mathrm{H}_{2} \mathrm{O}\right)$ or $\mathrm{NiSO}_{4}(10 \mathrm{mM})$ solution for $12,24,36$, and $48 \mathrm{~h}$. Means $\pm \mathrm{SD}, n=4$. Asterisks represent values that are significantly different between $\mathrm{H}_{2} \mathrm{O}$ and $\mathrm{NiSO}_{4}$ treatments at $P<0.05$ determined by Student's $t$-test. 
No differences in RWC were observed between Nitreated leaves and control leaves (Fig. 1). It appears that $\mathrm{Ni}$-induced proline accumulation is not attributed to the development of water stress. Previously, we also observed that proline accumulation in $\mathrm{Cu}$-exposed detached rice leaves and argued that this was due to $\mathrm{Cu}$ uptake per se, rather than to water stress (Chen et al. 2001).

The decrease in protein content was faster in $\mathrm{NiSO}_{4}$-treated detached rice leaves than in control leaves (Fig. 2). Therefore, protein degradation might contribute to $\mathrm{NiSO}_{4}$-induced proline accumulation in detached rice leaves. This suggestion is supported further by the observation that the content of total amino acids was higher in detached rice leaves exposed to $\mathrm{NiSO}_{4}$ solution than in control leaves (Fig. 2). It is generally considered that glutamic acid and ornithine can contribute to the accumulation of proline (Delauney and Verma 1993). The decreased or low content of glutamic acid was observed in $\mathrm{NiSO}_{4}$-treated detached rice leaves (Fig. 3), suggesting that glutamic acid is converted to proline in rice leaves exposed to excess $\mathrm{NiSO}_{4}$. Since $\gamma$-aminobutyric acid (GABA) content in $\mathrm{NiSO}_{4}$-treated detached rice leaves was observed to be higher than those in watertreated detached rice leaves (Fig. 3), therefore the decreased content of glutamic acid also resulted from glutamic acid being metabolized to GABA (Ireland and Lea 1999). The increase in glutamine content and decrease in glutamic acid in $\mathrm{NiSO}_{4}$-treated detached rice leaves (Fig. 3) also suggest that $\mathrm{NiSO}_{4}$ inhibits the conversion of glutamine to glutamic acid, a step catalyzed by glutamic acid synthase (Ireland and Lea 1999). Although ornithine may contribute to the accumulation of proline (Delauney and Verma 1993), slightly higher content of ornithine in $\mathrm{NiSO}_{4}$-treated detached rice leaves was observed to occur after proline accumulation (Fig. 3).

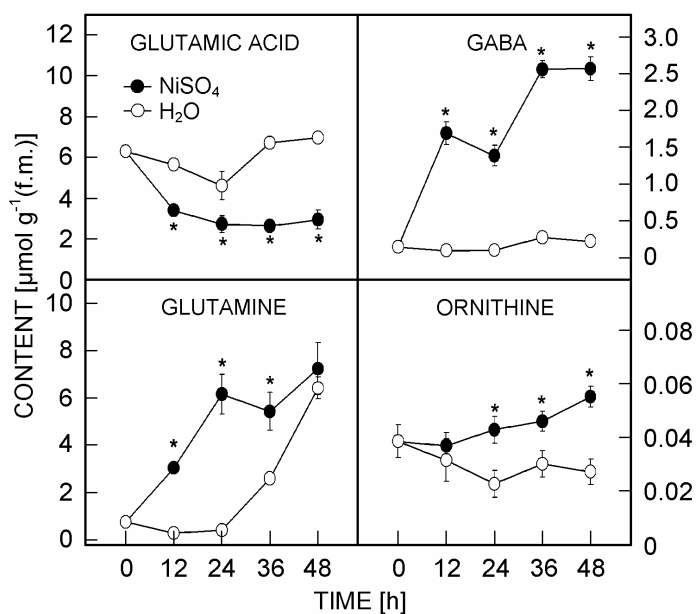

Fig. 3. The contents of glutamic acid, glutamine, $\gamma$-aminobutyric acid (GABA), and ornithine in detached rice leaves floating on water $\left(\mathrm{H}_{2} \mathrm{O}\right)$ or $\mathrm{NiSO}_{4}(10 \mathrm{mM})$ solution for $12,24,36$, and 48 h. Means $\pm \mathrm{SD}, n=4$. Asterisks represent values that are significantly different between $\mathrm{H}_{2} \mathrm{O}$ and $\mathrm{NiSO}_{4}$ treatments at $P<0.05$ determined by Student's $t$-test.
It appears that ornithine plays no important role in $\mathrm{Ni}$ induced proline accumulation in rice leaves.

To determine the role of biosynthetic pathway for proline accumulation caused by $\mathrm{NiSO}_{4}$, the effect of $\mathrm{NiSO}_{4}$ on P5CR and OAT activities was examined. It is obvious that clear differences in P5CR and OAT activities between $\mathrm{NiSO}_{4}$ - and water-treated detached rice leaves was observed at the later stage of incubation (Fig. 4), suggesting that P5CR and OAT play minor role in proline accumulation induced by $\mathrm{NiSO}_{4}$. It has been reported that PDH catalyzed proline oxidation (Hare et al. 1999). In the present study, PDH activity was found to decrease significantly in detached rice leaves exposed to excess Ni (Fig. 4), suggesting that decrease in proline oxidation (or degradation) contributes to proline accumulation in detached rice leaves under $\mathrm{NiSO}_{4}$ stress condition.

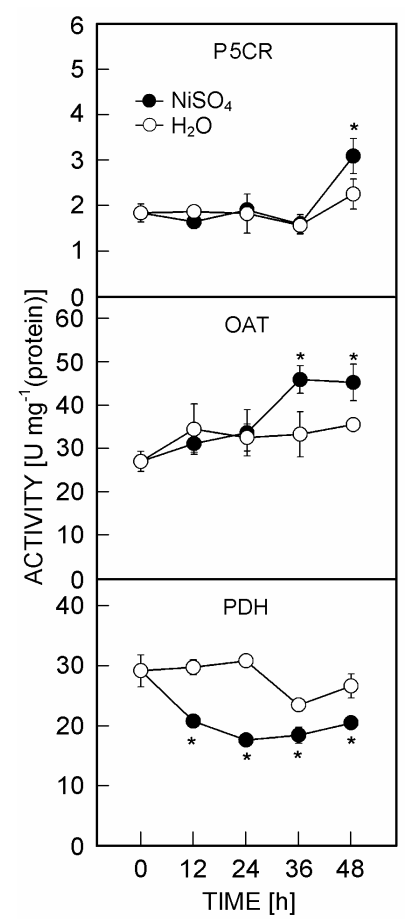

Fig. 4. The activities of $\mathrm{P} 5 \mathrm{CR}, \mathrm{OAT}$, and $\mathrm{PDH}$ in detached rice leaves floating on water $\left(\mathrm{H}_{2} \mathrm{O}\right)$ or $\mathrm{NiSO}_{4}(10 \mathrm{mM})$ solution for $12,24,36$, and $48 \mathrm{~h}$. Means $\pm \mathrm{SD}, n=4$. Asterisks represent values that are significantly different between $\mathrm{H}_{2} \mathrm{O}$ and $\mathrm{NiSO}_{4}$ treatments at $P<0.05$ determined by Student's $t$-test.

A decrease in proline utilization may also contribute to the accumulation of proline in $\mathrm{NiSO}_{4}$-treated rice leaves. To test this possibility, detached rice leaves were pretreated with $50 \mathrm{mM}$ ornithine for $3 \mathrm{~h}$ to increase the endogenous proline content and then transferred to water and $\mathrm{NiSO}_{4}$ for $24 \mathrm{~h}$ in the light; proline contents were then determined. It was found that the proline content was lower in the absence of $\mathrm{NiSO}_{4}$ than in the presence of $\mathrm{NiSO}_{4}$ (data not shown), suggesting that proline in detached rice leaves treated with $\mathrm{NiSO}_{4}$ is utilized less than in the absence of $\mathrm{NiSO}_{4}$. Less utilization of proline 
in detached rice leaves by $\mathrm{NaCl}$ has also been described previously (Lin et al. 2002).

The physiological significance of proline accumulation in intact rice leaves is not fully understood. Studying the effect of $\mathrm{NiSO}_{4}$ stress on enzyme activities involved in proline metabolism in intact rice leaves could provide valuable information on the physiological significance of

\section{References}

Ali, Pardha Saradhi, P.: Proline accumulation under heavy metal stress. - J. Plant Physiol. 138: 504-508, 1991.

Bassi, R., Sharma, S.S.: Changes in proline content accompanying the uptake of zinc and copper by Lemna minor. - Ann. Bot. 72: 151-154, 1993a.

Bassi, R., Sharma, S.S.: Proline accumulation in wheat seedlings exposed to zinc and copper. - Phytochemistry 33: 1339-1342, 1993b.

Bradford, M.M.: A rapid and sensitive method for the quantitation of microgram quantities for protein utilizing the principles of protein-dye binding. - Anal. Biochem. 72: 248254, 1976.

Brown, P.H., Welch, R.M., Cary, E.E.: Nickel: a micronutrient essential for higher plants. - Plant Physiol. 85: 801-803, 1987.

Charest, C., Phan, C.T.: Cold acclimation of wheat (Triticum aestivum): properties of enzymes involved in proline metabolism. - Physiol. Plant. 80: 159-168, 1990

Chen, C.T., Chen, L.M., Lin, C.C., Kao, C.H.: Regulation of proline accumulation in detached rice leaves exposed to excess copper. - Plant Sci. 160: 283-290, 2001.

Costa, G., Morel, J.-L.: Water relations, gas exchange and amino acid content in Cd-treated lettuce. - Plant Physiol. Biochem. 32: 561-570, 1994.

Delauney, A.J., Verma, D.P.S.: Proline biosynthesis and osmoregulation in plants. - Plant J. 4: 215-223, 1993.

Hare, P.D., Cress, W.A., Van Staden, J.: Proline synthesis and degradation: a model system for elucidating stress-related signal transduction. - J. exp. Bot. 50: 413-434, 1999.

Hsu, Y.T., Kao, C.H.: Abscisic acid accumulation and cadmium tolerance in rice seedlings. - Physiol. Plant. 124: 74-80, 2005.

Ireland, A.J., Lea, P.J.: The enzyme of glutamine, glutamate, asparagines, and aspartate metabolism. - In: Singh, B.K. (ed.): Plant Amino Acids. Pp. 49-109. Marcel Dekker, New York 1999.

Lin, C.C., Hsu, Y.T., Kao, C.H.: The effect of $\mathrm{NaCl}$ on proline accumulation in rice leaves. - Plant Growth Regul. 36: 275285, 2002.

Marschner, H.: Mineral Nutrition of Higher Plants. - Academic Press, New York 1995.

Metha, S.K., Gaur, J.P.: Heavy-metal-induced proline its accumulation. Regulation of proline accumulation in detached rice leaves under $\mathrm{NiSO}_{4}$ stress as we reported here is not necessarily similar to that in intact rice leaves. However, the results of the present work do provide some basic information which should be valuable for our future studies

accumulation and its role in amelioating metal toxicity in Chlorella vulgaris. - New Phytol. 143: 253-259, 1999.

Mishra, D., Kar, M.: Nickel in plant growth and metabolism. Bot. Rev. 40: 395-452, 1974.

Nakazawa, R., Kameda, Y., Ito, T., Ogita, Y., Michihata, R., Takenaga, H.: Selection and characterization of nickeltolerant tobacco cells. - Biol. Plant. 48: 497-502, 2004.

Rabe, E.: Stress physiology: the functional significance of the accumulation of nitrogen-containing compounds. - J. hort. Sci. 65: 231-243, 1990.

Rai, V.K.: Role of amino acids in plant response to stresses. Biol. Plant. 45: 481-487, 2002.

Schat, H., Sharma, S.S., Vooijs, R.: Heavy metal-induced accumulation of free proline in a metal-tolerant and a nontolerant ecotype of Silene vulgaris. - Physiol. Plant. 101: 477-482, 1997.

Tsai, Y.-C., Hsu, Y.T., Kao, C.H.: Proline accumulation induced by phosphinothricin in rice leaves. - Biol. Plant. 46: 213-320, 2003.

Vinterhalter, B., Vinterhalter, D.: Nickel hyperccumulation in shoot cultures of Alyssum markgrafii. - Biol. Plant. 49: 121124, 2005.

Wang, C.Y., Cheng, S.H., Kao, C.H.: Senescence of rice leaves VII. Proline accumulation is senescing excised leaves. Plant Physiol. 69: 1348-1349, 1982.

Weatherley, P.E.: Studies on the water relations of cotton plant. I. The field measurement of water deficit in the leaves. New Phytol. 49: 81-97, 1950.

Yang, C.-W., Kao, C.H.: Ammonium in relation to proline accumulation in detached rice leaves. - Plant Growth Regul. 30: 139-144, 2000.

Yang, C.-W., Kao, C.H.: Importance of ornithine- $\delta$ aminotransferase to proline accumulation caused by water stress in detached rice leaves. - Plant Growth Regul. 27: 189-192, 1999.

Yang, C.-W., Wang, J.W., Kao, C.H.: The relation between accumulation of abscisic acid and proline in detached rice leaves. - Biol. Plant. 43: 301-304, 2000.

Yoshiba, Y., Kiyosue, T., Nakashima, K., YamaguchiShinozaki, K., Shinozaki, K.: Regulation of levels of proline as an osmolyte in plants under water stress. - Plant Cell Physiol. 38: 1095-1102, 1999. 